H I G H L I G H T S

\section{IN BRIEF}

\section{DNA RECOMBINATION}

Global mapping of meiotic recombination hotspots and coldspots in the yeast Saccharomyces cerevisiae.

Gerton, J. L. et al. Proc. Natl Acad. Sci. USA 97, 11383-11390 (2000)

Microarray experiments usually involve a comparison of gene expression profiles, but Gerton et al. have used microarrays to assay the distribution of recombination events over the entire yeast genome at single-gene resolution. The strongest association seen is between hotspots of recombination and elevated $\mathrm{G}+\mathrm{C}$ content, and the goal is now to relate the positions of hotspots and coldspots - to chromosome structure.

\section{GENE EXPRESSION}

Genomic analysis of gene expression in C. elegans. Hill, A. A. et al. Science 290, 809-812 (2000)

Comparative genomics and microarray analysis of gene expression are a potent combination. In this first, comprehensive analysis of gene expression in animal development, the authors find that Caenorhabditis elegans genes conserved in Drosophila melanogaster and yeast tend to be expressed at higher and more uniform levels during development. Worm-specific genes, however, are more likely to be developmentally regulated observations consistent with the view that ancient genes deal with the 'core' functions, whereas newer genes see to worm-specific developmental processes.

\section{TECHNOLOGY}

Specific mutations induced by triplex-forming oligonucleotides in mice.

Vazquez, K. M. et al. Science 290, 530-533 (2000)

One gadget missing from the geneticist's toolkit is a technique to introduce targeted mutations into somatic cells. Vazquez et al. have achieved this in the somatic cells of adult mice using triplexforming oligonucleotides (TFOs), which recognize and bind to specific duplex DNA sequences. TFO's seem to increase the hypermutability of G-rich, recombinogenic sites and, although their mechanism of action remains unknown, their mutagenic activity depends on a functioning nucleotide-excision-repair system.

\section{DISEASE MODEL}

Identification of genes that modify ataxin-1-induced neurodegeneration.

Fernandez-Funez, P. et al. Nature 408, 101-106 (2000)

The power of using flies to study human neurodegenerative disease is convincingly illustrated in this study, in which the authors expressed the human $S C A 1$ gene, encoding transcripts with and without expanded polyglutamine repeats, in the Drosophila melanogaster eye. They then used these flies in genetic screens to identify modifiers of the eye neurodegeneration phenotype. The modifiers they identified point to new mechanisms of polyglutamine pathogenesis and implicate protein folding and protein clearance in SCA1 aetiology.

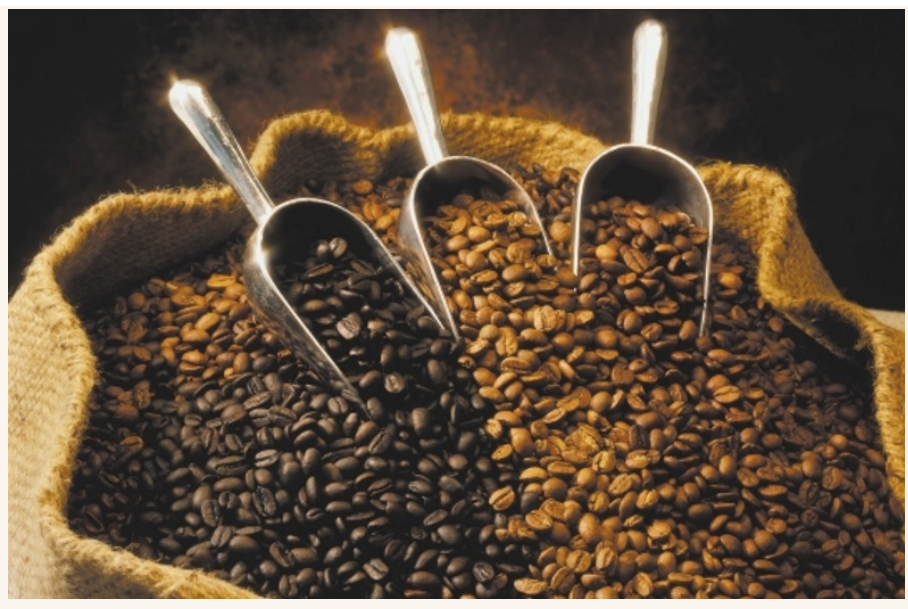

POPULATION GENETICS

\title{
Founding populations: Colombian blend?
}

When the Spanish colonized Colombia in the sixteenth century, they brought with them many new influences: their religion and culture, slaves from West Africa, and European diseases that decimated the local Amerind population. Colombia's history of colonization, together with the obstacle to human mobility imposed by the Andes, made Carvajal-Carmona et al. question whether Colombian populations could be used to map complex traits. This is because the country's past combines two potential sources of linkage disequilibrium (LD) — recent founding by a small number of individuals and population admixture.

The authors studied 80 individuals descended from the northwestern Colombian province of Antioquia a region settled by the Spanish in the seventeenth century. These individuals were typed for mitochondrial DNA (mtDNA) and Y-chromosome markers to identify the origins of their ancestors. Their findings - that $94 \%$ of Antioquian $\mathrm{Y}$ chromosomes are European and 90\% of the Antioquian mtDNA gene pool is Amerind in origin - are perhaps not surprising given the colonial history of the region. These results confirm that local Amerind women predominantly had children with Spanish colonists and that this, combined with disease and colonial attack, almost eliminated the Amerind male gene pool from today's Antioquian population. A comparison of Antioquian Ychromosome allele frequencies with those from the Iberian peninsula and northern Africa (because Spain was under Moorish rule between the eighth and fifteenth centuries) showed that the European founders were predominantly from southern Spain, but also that a fraction of founders came from the northern Basque region and that others had a Sephardic ancestry.

Previous blood-group data had showed the genetic background of Antioquians to be predominantly ( 70\%) white. The researchers suggest that this could be accounted for by there having been more male founders than female ones. Furthermore, colonial culture pressured Spanish men into having families with mixed-race rather than with Amerind women, further reducing the incorporation of additional Amerind female founders into the expanding population.

So does the Antioquian population have LD levels that would make it useful for mapping complex traits? It remains an open question. Although the mtDNA data indicate that it was isolated for some time, the level of founder diversity suggests that a strong population bottleneck did not occur at founding. However, the researchers remain hopeful that the presence of population sub-isolates within this large region may yet prove this founding admixture to be a fruitful blend.

\section{Jane Alfred}

20) References and links ORIGINAL RESEARCH PAPER CarvajalCarmona, L.G. et al. Strong Amerind/white sex bias and a possible sephardic contribution among the founders of a population in northwest Columbia. Am. J. Hum. Genet. 67, 1287-1295 (2000)

FURTHER READING Sans, M. Admixture studies in Latin America: from the 20th to the 21st century. Hum. Biol. 72, 155-177 (2000) WEB SITE Andrés Ruiz-Linare's lab 